Document downloaded from:

http://hdl.handle.net/10251/104227

This paper must be cited as:

Mars, L.; Ruiz Sánchez, T.; Arroyo-López, MR. (2018). Identification of determinants for rescheduling travel mode choice and transportation policies to reduce car use in urban areas. International Journal of Sustainable Transportation. 1-11.

doi:10.1080/15568318.2017.1416432

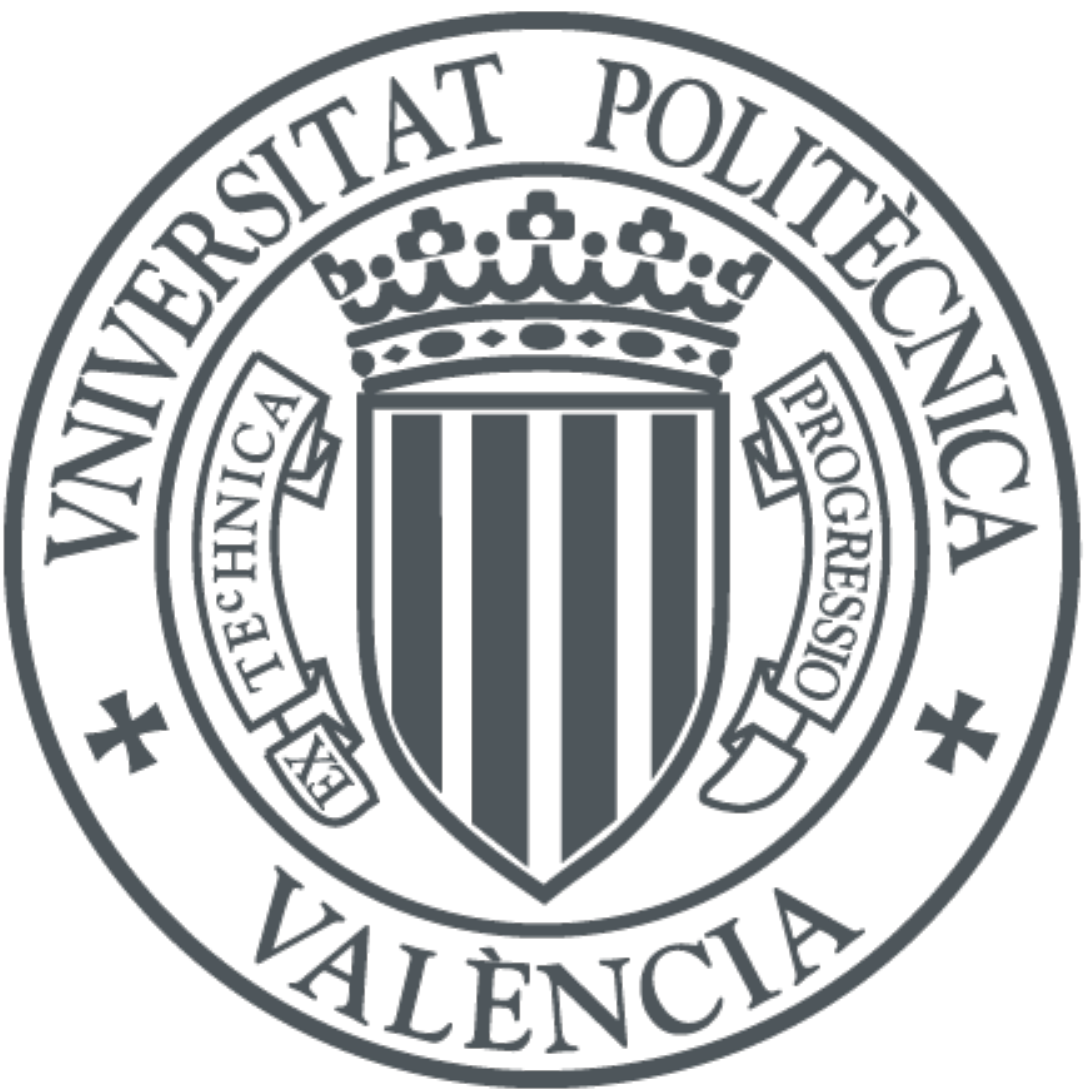

The final publication is available at

http://doi.org/10.1080/15568318.2017.1416432

Copyright Taylor \& Francis

Additional Information 


\section{IDENTIFICATION OF DETERMINANTS FOR RESCHEDULING TRAVEL MODE CHOICE AND TRANSPORTATION POLICIES TO REDUCE CAR USE IN URBAN AREAS}

\section{Lidón Mars, Corresponding Author}

Researcher

Social Psychology Department

Faculty of Psychology

Universitat de València,

Avda. Blasco Ibáñez.21

46010, Valencia, Spain

Tel: $(+34) 963983940$

Email: m.lidon.mars@uv.es

\section{Tomás Ruiz}

Associate Professor

Transport Department, School of Civil Engineering

Universitat Politècnica de València

Camino de Vera $\mathrm{s} / \mathrm{n}$

46022 Valencia, Spain

Tel: $(+34) 963877376$

Fax: (+34) 963877379

Email: truizsa@tra.upv.es

\section{Rosa Arroyo}

Researcher

Transport Department

School of Civil Engineering

Universitat Politècnica de València

Camino de Vera s/n

46022 Valencia, Spain

Tel: $(+34) 963877375$

Fax: (+34) 963877379

Email: maarlo3@cam.upv.es 


\section{ABSTRACT}

This paper presents a qualitative analysis about the determinants related to rescheduling travel mode decisions during the activity scheduling process. Notably, we were interested to study changes between intention and behavior. Data used came from an in-depth CATI follow up survey to habitual drivers carried out during the implementation of a panel survey. An interpretative qualitative method based on Analytic Induction was used to cope with the complex nature of rescheduling decisions and the characteristics of the data. The Theory of Planned Behavior has been used to gain a better understanding of the reasons associated with rescheduling travel mode decisions and to obtain a possible explanation of the phenomena studied.

In our sample, 12 codes were identified as the main determinats of travel mode changing. Main reasons for rescheduling a travel mode are different considering gender, age and the type of travel mode change. Main reasons for changing a non-private pre-planned travel mode to a private travel mode are different considering the type of travel mode preplanned. New determinants of rescheduling decisions different from those associated with other activity scheduling decisions previously identified emerge when analyzing travel mode changes. A number of important sustainable transportation policies to reduce car use in urban areas are derived from the results of this study.

Keywords: Travel Mode Rescheduling, Qualitative Analysis, Activity Scheduling Process, Sustainable Transportation. 


\section{INTRODUCTION}

In recent years, a wide concern about environmental damage has arisen, in particular carbon emissions and noise levels, caused by car use in urban areas. To diminish this problem, policy measures target the reduction of private transportation use by promoting the alternatives such as public transportation bicycles and walking. These measures would also help to make urban traffic more fluid and lessen parking problems in some areas (Gardner and Abraham, 2007; Thomas, Walker and Musselwhite, 2014). To design efficient transportation measures to change travel behavior, it is necessary to study how individuals make their decisions about the travel mode they use. It is particularly interesting to analyze why people reschedule their preplanned activities and travels.

Activity rescheduling is part of a larger unobserved decision-making process that involves planning and execution of activities over time (Doherty and Miller, 2000). Understanding the rescheduling process has proved very important in the context of traffic management (Habib, Sasic, Weis and Axhausen, 2013; Nijland, Arentze, Borgers and Timmermans, 2009), evaluating adequately the impact of transportation policy measures towards reducing car use in urban areas (Chen and Chao, 2011) or assisting urban and transportation planning to react to unexpected events (Chen, Gärlin and Kitamura, 2004). The success of policies such as tolling, congestion pricing, and travel demand management depends on how people might adjust their daily activity and travel patterns to the enforced changes in their everyday lives (Axhausen and Gärlin, 1992).

\subsection{Existing theoretical frameworks}

Most theoretical frameworks applied to study the problem of short and medium-term rescheduling travel decisions are developed from the activity-based approach. The foundation of the activity-based approach can be dated back to Hägerstrand (1970) and his colleagues. He 
drew attention to the fact that people's choices may be strongly affected by various types of constraints. In particular, he differentiated between capacity, coupling and authority constraints. In contrast to Hägerstrand, Chapin (1974) stated that individual decisions are made based on desires and opportunities rather than on constraints. On the other hand, Cullen and Godson (1975) were the first to present the activity scheduling process and introduced the concept of flexibility to explain the likelihood of rescheduling associated with activities and travel episodes.

On the other hand, a number of psychological theories have been used to examine this decision-making process in relation to transportation planning, for example the Theory of Human Motivation, Hierarchy of Needs (Maslow, 1943) and the Social Cognitive Theory (Bandura, 1986). Recent studies have applied these theories to the fields of walking decisionmaking and developing a transit-training program for the elderly to decrease their use of cars and increase their use of buses and transit information resources (Shaheen, Allen \& Liu 2008; Mateo-Babiano, 2016).

Another particularly useful theory in the present study is the Theory of Planned Behavior (Ajzen, 1991). It proposes that the intention to carry out a particular behavior depends on the individual's attitude toward that behavior, subjective norms, and perceived behavioral control. This theory has been frequently employed to predict behavioral intention because it is based on behavior (Lois, Morinao and Rondinella, 2015). It attempts to predict behavior based on an individual's preexisting intentions, attitudes, and motivations in relation to a particular circunstance. Behavior and intention are composed of different elements: the action or type of behavior and what it is directed toward; the context or place, and the concrete time in which it occurs. Therefore, intention and behavior will correspond to the degree to which these elements match in magnitude (Azjen and Fishbein, 1980; 2005). 


\subsection{Activity-travel rescheduling data and analysis}

Exploring the reasons behind activity-travel rescheduling decisions is a challenging task. Changes between the preplanned and the executed schedule are not only determined by a single factor, but by a combination of interacting factors, some of which are difficult to measure. Researchers have used two main techniques for collecting data related to rescheduling activities and trips. Firstly, they have used attitudinal surveys and experiments. These methods include travel-related adaptation strategies (Cao and Mokhtarian, 2005), and hypothetical scenarios in which respondents are prompted to update a pre-planned agenda of activities and trips (Chen et al, 2004; Nijland et al, 2009; Arentze and Timmermans, 2000). Secondly, they have used data collection to compile pre-planning and executing activity-travel schedules. These surveys consist of asking respondents to detail their pre-planned agenda for a number of days in the near future, to describe the characteristics of activities and trips actually implemented in those days, and to provide additional information related to the scheduling decisions made between pre-planning and execution (most representative: Auld, Williams, Mohammadian and Nelson, 2009; Clark and Doherty, 2010; Doherty and Miller, 2000; Ruiz, 2005). The use of data coming from open-ended questions about the reasons associated with those changes can substantially enhance the study of rescheduling processes. Those questions allow people to express their thoughts with little influence from the interviewer and without the bias of a survey consisting of asking respondents to choose from predefined choices.

To analyze the activity and trip rescheduling data, several approaches have been adopted. Constraint-based models examine whether an individual activity agenda is feasible within particular space-time constraints (Jones, Dix, Clark and Heggie, 1983). Utilitymaximization approaches are based on the premise that individuals maximize their utility when organizing their daily schedule (Ben-Akiva, Bowman and Gopinath, 1996). Computational or rule-based models use decision heuristics to avoid the uncertainty inherent in the analysis of 
utility maximization methods (Arentze and Timmermans, 2000; Roorda, Miller and Habib, 2008).

Previously in this study, the behavioral theories have been exposed but they do not provide sufficient tools for the construction of a solid framework of determinants that directly affect activity-rescheduling behavior. Qualitative research is a good method to expand on and complete those theories as well as to analyze information collected from open-ended questions (Clifton and Handy, 2001). Qualitative methodology is a research approach that allows the exploration of the phenomenon within its context not only through one lens, but rather a variety of lenses. This characteristic permits the comprehension of the phenomenon throught the consideration of a wide range of its facets (Flick, 2014). Clark and Doherty (2010) used a qualitative approach to analyze rescheduling decisions from data collected with open-ended questions related to those decisions. They identified the following causes or impetus for adding, deleting or modifying activity-travel attributes: personal choices, conflict-scheduling issues, interpersonal factors, and personal needs. More recently, Mars and Ruiz (2016) concentrated on studying elimination decisions during the activity scheduling process. They used a larger sample, and combined qualitative and quantitative methods of analysis. They identified two reasons for trip elimination decisions (activity location change and activity suppression) and eight reasons for activity elimination decisions (social, weather, mandatory activity, discretionary activity, maintenance activity, resources, activity timing/duration, and location change).

\subsection{Travel behavior and mobilities studies}

Travel Behavior literature related to transit and active transportation is a growing area of research. For example, some studies have analized the influence of urban design on children's physical activity or pointed barriers that car users find to do not walking for short distances 
(Badlan and Schofield, 2005; Loukopoulos and Gärling, 2005). Others have studied the characteristics of the bicycle infrastructure to promote cycling or reviewed strategies to promote physical activity replacing short car trips with active transportation (Dill, 2009; Maibach et al, 2009). Millward et al. (2013) studied the characteristics of active transportation, in particular walking behavior, in terms of destinations, durations and distances. More recently, Ferrer et al. (2015) studied the elements of the built environment that facilitate short walking trips and Wuerzer and Mason (2015) analyzed cycling trips characteristics among college students. Additionally Helbichet et al. (2016) have described how neighborhoods with pronounced land-use diversity make trip chaining via active transport modes more convenient.

On the other hand, Mobilities research has done great work in opening up transport studies to qualitative interpretation, including on sustainability. For example, FreudendalPedersen et al. (2017) described methods to support planners at creating more sustainable mobilities, underliying the "why" and the "for what" in order to achieve more effective projects. Sattlegger and Rau (2016) used a qualitative mobility biographies approach to identify patterns of meaning that shape the mobility decisions and practices of individuals, which opens possible opportunities for mainstreaming carless mobility practices. Kent et al. (2017) used a qualitative analysis of interview data to explore the period during which individuals adopt car sharing. They found that disruption usually preceds the transition that lead to travel mode change. Mobility transitions are preconditioned by ability and willingness to change.

Scholars are also waking up to socio-cultural ideas of why people travel, how decisions are made on the fly and how behaviours are unpredictable. Not only are gendered the choices of where, how fast, how often, etc., people travel. Moreover, narratives, discourses and travel modes' representations are different by gender as well (Cresswell and Priya Uteng, 2008). Freedom of movement and fast mobilities associated with the use of car (Elliot and Urry, 2010) explain to some extent the negative attitudes towards public transport existing during the second half of the twentieth century in developed countries. However, it is argued that private 
car is losing its significance in favour of intermodal transport (Canzler, 2016). This is because restrictions on car use to mitigate climate change are fostering the interlinking of different modes of transport into integrated mobility services based on digitalisation and the use of information and communication technologies. Most of traditional transport policies have focused on reducing travel times. However, the perception of time has evolved over the past decades. Peters (2005) argued that travel not only takes time, it also makes time. Mokhtarian (2005a, 2005b) found that travel time is not always perceived as a cost. More recently, Hau and Edmondson (2013) have described fundamental changes in how individuals, households and societies view and use time in a more sustainable way. These changes justify the design and implementation of alternative transport policies.

In this study, we analyze open-ended questions concerning the reasons associated with changes between pre-planning and executing trips. In particular, we focus on changes on travel mode. The objective of this study is to identify determinants that influence the decision to modify the pre-planned use of specific travel modes. We use a qualitative methodology approach, which is very scarce in the literature of travel behavior, and almost inexistent in the context of the activity scheduling process. To this end, we develop a new methodology adapted from Taylor and Bogdan's (1975) version of Analytic Induction. This approach could be aligned with those methodologies including in the Mobilities Methods described by Urry (2007), in particular "after the fact interviews". Furthermore, qualitative studies of travel behavior usually lack any explanation of the process followed to establish either the codification used or the justification of the selected qualitative methodological approach, which is compulsory when applying qualitative techniques (Flick, 2014). Those aspects are thoroughtly considered in this paper.

Section 2 explains the data collection methodology, characteristics of the sample, and the qualitative method used to analyze the data. Section 3 describes results associated with reasons for rescheduling travel modes by demographics; reasons for rescheduling by type of 
travel mode change; and reasons for rescheduling pre-planned non-private travel modes. Section 4 includes a discussion of the previous findings. And Section 5 presents the main conclusions.

\section{METHOD}

\subsection{Design}

The survey consisted of three phases. In the preliminary stage, face-to-face interviews were carried out to generate a pre-planned activity-travel agenda for the following week, starting the day after the interview. Participants were asked to define only the characteristics of the activities and travels that were certain to be carried out, and leave blank the rest of the weekly agenda. Before finishing the interview, respondents received a mobile phone with an activitytravel diary implemented. The second phase was developed during the research week, because respondents had to complete the activity-travel diary to collect characteristics (initial time, duration, location, etc.) of activities and travels as they were executed. Information was sent in real time to the research group, who manually compared pre-planned agendas and observed activities and travels. Finally, during the third phase of the survey, an in-depth telephone interview was carried out to ask the subject about the causes of the differences found. Some of the questions asked were:

- Why did you decide not to carry out/modify/perform that activity/trip?

- When did you decide not to carry out/modify/perform that activity/trip?

- $\quad$ Did the decision depend on another change in a previous activity/trip?

- Did the decision depend on the possibility of carrying out a secondary activity?

- Was the decision taken with/influence by another person? 
There were also specific questions pertaining to the type of decision. In particular, for modification decisions, respondents were asked if they considered other alternatives to modify the activity or trip. For more details, see Ruiz and García-Garcés (2015).

To analyse the answers to the above questions, in this work it has been used an interpretative qualitative method, in particular Content Analysis (CA). This method consist on analyzing the responses step by step and classifying them into content analytical units, named categories or codes, each of which represents determinants of travel mode changing. To this end, we have followed an inductive category development method: Analytic Induction (AI) originally developed by Znaniecki (1934). A detailed description of the application of this method can be found in the Analysis section.

\subsection{Participants}

Respondents belong to a larger study where an activity scheduling process panel survey was carried out within the framework of a project that lasted two years in the city of Valencia (Spain), with the objective of assessing the effects of travel behavior change programs (Ruiz and García-Garcés, 2015). Participants were recruited at parking slots in Valencia, after which they participated in a survey to assess their willingness to change from car to biking or walking. All respondents were habitual car users. 165 respondents successfully completed the survey. The sample gave good representation of gender and and activity status, but older people were underrepresented.

As previously explained, we have focused our research on a particular modify decision, it being the alteration of a preplanned travel mode pertaining to a trip episode. After removing those answers that did not provide valid information regarding the reasons of travel mode rescheduling, 473 valid responses provided by 131 people were analyzed. This relatively high number of reschedulings can be explained by two reasons. Firstly, because each participant provided the characteristics of pre-planned trips for a week-long period. Secondly, because 
many reschedulings generated other reschedulings later in the day, as it is found in the study. So the data analyzed in this paper relates to the reasons they gave for modification decisions relating to travel modes.

\subsection{Analysis}

Our methodology drawns on Taylor and Bogdan's (1975) version of AI. They proposed several steps to define hypotheses and to recognize themes during the qualitative analysis. We adapted aspects of their proposal as follows:

1. The first step consisted of defining a coding frame by structuring the information from the selected material, extracting themes, and formulating hypotheses. This coding frame and the use of theory-based categories resulted in a first list of codes.

2. The second step was to reassess the data with greater emphasis on the context at the point of its collection. The open-ended responses were analyzed within the context of the individuals' agenda (taking into account pre-planned and executed anterior and posterior activities).

3. The third step was coding. This part of the analysis involved deciding how to differentiate and combine the data retrieved to better reflect the information (Milles and Hubermann, 1994). Two researchers coded the same dataset and discussed the difficulties, following conventional triangulation procedures. This would support the principle in case study research that the phenomena are viewed and explored from multiple perspectives (Baxter and Jack, 2008). The data collection and comparison enhanced data quality based on the principles of idea convergence and confirmation of findings (Knaft and Breitmayer, 1989). To measure this triangulation process, Cohen's Kappa measure (1960) of agreement was employed, which is defined as

$$
\text { Percentage agreement }(\text { kappa })=\frac{\text { agreements }}{\text { agreements }+ \text { disagreements }}
$$


First, the two researchers, individually, read the answers and atempted to discern which could be categorized and which fell outside the scope of the study. If a participant gave several reasons for rescheduling, the reason coded was the first mentioned. This initial classification resulted in six categories (i.e. Activity change, Activity location change, Weather, Convenience, Resources, and Social). Subsequently, both researchers reviewed approximately 25 percent of cases and they agreed to introduce new codes, and proceeded individually to categorize all cases. From this second classification, two of the six categories were redefined and three codes were added, making nine in total: Weather, Convenience, Resources, Social, Fatigue, New activity, Location change of a pre-planned activity, Sharing the car, and Opportunity.

The researchers reviewed at random aproximately twenty-five percent of the responses. As a result, a third codification arose with sixteen categories (i.e. Weather; Convenience; Resources; Social influences; Personal needs; Travel needs; Trip attributes; Location change of a pre-planned activity; Location of a new/added activity on the schedule; Number of companions; Decision to share a car; Opportunity/new travel option; Parking availability; Travel (subjective) preference; Perceived behavioral control; and Constrained use of a travel mode). The researchers met for a fourth time to crossreference the two codifications in order to ensure mutually agreed definitions. Following this meeting, four codes were discarded.

The final codification adopted included 12 codes. The percentage of agreement of the final codification ranged from $84.8 \%$ to $100 \%$. So according to Landis and Koch (1977) the agreement was almost perfect $(81 \%-100 \%)$. According to Fleiss (1981), the agreement was excellent $(>75 \%)$. The definitions are detailed below. Examples for each code are included in Table 1.

- Constrained: When respondents refer to the decision to change travel mode for a previous trip, which conditions the use of the same mode in later trips. This reason was usually accompanied by disappointment. 
- Location change of a pre-planned activity: This refers to all reasons where the main issue is related to a change in the location of an anterior or posterior pre-planned activity. It may be simply a change of location without further details provided, or an indication that the new location of the activity is nearer or farther than the previous pre-planned location.

- Resources: This refers to issues related to travel mode alternativities that are provided (or limited) by ownership or personal availability, most frequently car ownership or availability. The decision to use a transportation mode because it is available - to do something not pre-planned - is also codified within this category.

- Location of a new/added activity: This refers to all reasons related to the location of a new non-pre-planned activity. It may be simply a new location without further details provided. This new activity location may be nearer or farther than the previous preplanned activity location and may thus impact the following pre-planned activity location.

- Social influence: This refers to reschedulings that are primarily caused by the direct influence of other people, such as family, household members (including boyfriends, girlfriends and housemates) and friends.

- Opportunity/new travel option: This refers to opportunities to use a different travel mode to the one that had been pre-planned. Being that alternative provided by others.

- Weather: This refers to reasons relating to good or bad atmospheric conditions.

- Travel needs: This refers to reasons concerning travel-related attributes associated with individual needs, such as restrictions and availability pertaining to personal schedules.

- Decision to share a car: This refers to the active intention to share a vehicle with relatives, friends or colleagues.

- Travel (subjective) preference: This relates to spontaneous personal decisions to reschedule a travel mode based on likes and dislikes. 
- Personal needs: This refers to decisions related to travel modes chosen to fulfill personal and practical requirements, such as security, safety, carrying luggage, fatigue or bad-health.

- Habit: This refers to the reasons for any particular case consisting of car driver changing to car companion or vice versa, depending on the presence of the usual driver.

\section{TABLE 1}

\section{FINDINGS}

Taking the sample as a whole, the code most frequently mentioned was Constrained (Table 1): rescheduling the travel mode as a consecuence of a previous change wich has compelled the subject to employ the same mode in subsequent trips $(15.0 \%)$. The need to change the travel mode for a particular trip very often eliminates any option to use the pre-planned travel mode for subsequent trips. Respondents mentioned this reason in two ways: in the first case, people take advantage of that situation and use that travel mode to add activities or perfom them in a far away place, e. g. when they change a non private vehicle to a private vehicle to go to work, they usually add a shopping activity at a far away mall. However, respondents also mention this reason with disappointment, because they are commited to that travel mode for the rest of the day.

Other important code was Location change of a pre-planned activity $(12.5 \%)$. The change of the location where the pre-planned activity is now going to be performed affects the decision to reschedule the travel mode. Respondents usually refer to the distance to the new location: nearer or farther away than the pre-planned location. Therefore, distance is one of the main characteristics considered by respondents when rescheduling their travel mode to perform the planned activity, e.g. car to walking or vice versa. In the same way, the location of spontaneous (11.2\%; new activities, not preplanned) activities is also an important reason for rescheduling travel modes. Once again, in some cases respondents mentioned the distance of 
the new activity location as a factor in changing their travel mode. Adding new activities that are closer or more remote may mean that the pre-planned travel mode is no longer necessary, either due to issues related to distance or due to the need to keep the rest of their agenda intact.

The distance to the new location (both for pre-planned and spontaneous activities) is an influence that could be aligned with the (physical) environmental factors from the Social Cognitive Theory of Bandura, which determines behavioral change. Travel behavior studies have highlighted the importance of the distance in the context of active transportation as well. For example, Loukopoulos and Gärling (2005) showed that car users may be averse to the physical efforts required by walking, and that travel distance may be an important barrier for use of such active transport. More recently, Millward et al. (2013) found that all major walking destinations show strong distance-decay effects: most walks are shorter than 600 metres $(\mathrm{m})$, and very few exceed $1200 \mathrm{~m}$. The analysis of Wuerzer and Mason (2015) suggests that cycling distance appears to be about 3-4 miles among college students. Ferrer et al. (2015) identified a minimum walking distance below 10-20 min where trips were very likely to be undertaken walking.

Additionally, longer distances to activity locations place a higher importance on speed and convenience of travel modes. The speed is an important characteristic that contributes to the feeling of freedom associated with car (Sheller \& Urry, 2000). In contrast, public transportation tends to be associated with inflexibility, impunctuality, slowness and poverty, or, as it were, highly negative social values within modern, progressive and neoliberal thinking (Manderscheid, 2014).

\subsection{Reasons for rescheduling travel modes by demographics}

Table 1 includes examples of the answers provided by respondents for each category. To find out if there are significant differences between distributions of reasons for travel mode change (categories) and demographic characteristics, and types of travel mode reschedulings, 
we use chi-square test for independence. This test compares two variables in a contingency table to see if they are related. In a more general sense, it tests to see whether distributions of categorical variables differ from each another. The chi-squared statistic $\left(\chi^{2}\right)$ is a single number that tells you how much difference exists between your observed counts and the counts you would expect if there were no relationship at all in the population.

250 responses were provided by men $(52.9 \%)$ and 223 by women $(47.1 \%)$ from the total opened answers available. In this study, the rescheduling reasons are distributed differently according to gender (Table 2).

\section{TABLE 2}

In our sample, the most frequent reason for change given by men is Constrained (16.8\%). "I drove because I came out a little bit later from home, and I had to go by car" [male 40 years old, change from subway passenger to car driver]. Another important reason is Location change of a pre-planned activity $(12.8 \%)$. Other reasons given by male respondents are Resources (11.6\%) and Weather (11.2\%).

In contrast, for women in our sample the most frequent reason to reschedule travel modes is Social influence (15.7\%). "I drove my children to my mother's house because my sister's child was ill and they had gone to the doctor" [female, 38 years old, change from pedestrian to car driver]. The second most important is Location of a new added activity $(13.9 \%)$. Constrained is third in frequency $(13.0 \%)$. Location change of a pre-planned activity is also important $(12.1 \%)$.

The rescheduling reasons are distributed differently according to age as well (Table 2). The most frequent reason to change travel mode in our sample for those below 50 years old is Constrained (younger: 15.2\%; middle-aged: 14.7\%). "I drove back instead of walking because I had already used my brother-in-law's car to go there" [male, 32 years old, change from 
pedestrian to car driver]. The second most important reason for those below 50 years old is Location change of a pre-planned activity (younger: 12.7\%; middle-aged: $13.1 \%$ ). There are also other important reasons for those below the age of 30, such as Opportunity/new travel options (11.7\%), and Weather (11.7\%).

In the case of middle-aged respondents, other important reasons are Resources (12.2\%), Location of a new/added activity (11.4\%) and Social influence (10.6\%).

For those over 50, the most important reason is Resources (25.8\%). "I went by bus because my son took my car because his had broken", [male, 59 years old, change from car driver to urban bus passenger]. Another important reason is Social influence (22.6\%).

Contrary to Clark and Doherty's findings (Clark \& Doherty, 2009), our results indicate that demographics are significantly associated with reasons for rescheduling travel modes. Considering that the sample size is very similar in both studies, it could be possible that these differences might be related to the fact that Clark and Doherty's study focused on global changes in the schedule (additions, deletions and modifications). On the contrary, the present study focuses on the rescheduling of a particular trip attribute: travel mode. Besides, these differences could be explained by cultural and social standards specific to each location.

\subsection{Reasons for rescheduling by type of travel mode change}

To carry out this analysis, travel modes have been divided into two groups. On the one hand, cars and motorbikes, whether used by a driver or passenger, have been classed as private vehicles (PV). On the other hand, all other travel modes (i.e. urban bus, subway, cab, bicycle, pedestrian, and multimodal trips) have been classed as non-private vehicles (NPV) (Table 3). This will allow the scrutiny of any differences between changing to a more or less environmentally friendly travel mode.

TABLE 3 
There are significant differences in how the reasons given for alterations are distributed between the pre-planned PV and the PV actually employed or the decision to use a NPV. In the first instance, the most frequent reason in our sample is Social Influence (18.8\%). "Because my boyfriend took me home" [female, 22 years old, change from car driver to car passenger]. The second most important reason to change from one PV to another PV is Constrained (16.3\%). Other important reasons are Opportunity/new travel option (15.6\%), and Resources $(15.6 \%)$.

Regarding the change from PV to NPV, the most frequent reason identified in our sample is Location change of a pre-planned activity (19.6\%). "We went to the nearest beach" [female, 28 years old, change from car driver to pedestrian]. Other important reasons are Resources (18.5\%) and Location of a new/added activity (17.4\%).

There are also significant differences in the distribution of categories (Table 3 ) between pre-planning a trip by NPV (i.e. neither car nor motorbike) and executing it by PV (e.g. changing from urban bus passenger to car driver), or pre-planning a trip by NPV and executing it by a different NPV (e.g. changing from bicyclist to urban bus passenger).

When pre-planning a trip by NPV and executing it by PV, the most frequent reason in our sample to change the travel mode is Constrained (21.3\%). "Because before that I had to drive to carry out previous activities" [male, 47 years old, change from pedestrian to car driver]. The second most frequent reasons are Location of a new/added activity (14.0\%) and Location change of a pre-planned activity (14.0\%). Another important reason is Opportunity/new travel option $(10.7 \%)$.

Concerning the changes between pre-planning a trip by NPV and executing it by another NPV, the most frequent reason in our sample is Location change of a pre-planned activity (23.3\%). "Because I had eaten at my workplace and my other work was too far away" [female, 37 years old, change from pedestrian to urban bus passenger]. Other important reasons are Resources (16.3\%) and Travel needs (16.3\%). 


\subsection{Reasons for rescheduling pre-planned non-private travel modes}

Finally, we are particularly interested in studying the reasons associated with the change of an intention to use NPV travel modes, in order to implement the trip by a PV travel mode. Table 4 shows the distribution of codes/determinants of each pre-planned NPV mode.

\section{TABLE 4}

In our sample, more than half of the cases are related to pre-planned pedestrian trips that ends up being executed by PV. The most important reason given to change the intention to walk and implement the trip instead by PV is Constrained (21.6\%). "As I had to drive (to see my friend) I also had to drive back" [male, 26 years old, change from pedestrian to car driver]. Other important reasons are Location change of a pre-planned activity (18.9\%), Location of a new added activity (16.2\%), and Weather (11.7\%).

Constrained together with Opportunity / New travel option are the main reasons for changing the intention to use a NPV other than walking and to execute the trip by PV (20.9\%). "The friend with whom I was having coffee took me home in his car" [male, 40 years old, change from urban bus passenger to car passenger].

\section{DISCUSSION}

\subsection{Reasons to reschedule travel modes}

A dataset containing 473 reasons to reschedule travel modes has been analyzed using Content Analysis qualitative methodology. The result is the identification of 12 categories, which reflect the determinants for such modification decisions. In our sample, the most frequent reason given for changing the pre-planned travel mode when executing a trip is the influence of a previous decision to change. Therefore, there is a need to study the remaining determinants to look for 
a reason that explains the first travel mode rescheduling, and whether it is possible to avoid that second negatively perceived instance.

Constrained decisions emphasize the importance of considering the interdependencies among trip links in trip chains with multiple non-home stops, has been recognized largely in the travel behavior literature (Adler \& Ben-Akiva, 1979; McGuckin \& Murakami, 1999; McGuckin, Zmud \& Nakamoto, 2005; Kitamura, 1984). More recently, Helbichet et al. (2016) have described how neighborhoods with pronounced land-use diversity make trip chaining via active transport modes more convenient.

The determinants identified related to constrained decisions, and changes of locations (for both pre-planned and new activities) are factors related to interactions and conflicts in the activity agenda. Activity scheduling decisions are tightly connected and dependent on one another. These findings highlight the need to study rescheduling decisions in the context of their interrelations with other activities and trips in the agenda.

The influence of other people was the most important rescheduling reason given by females in our study, whereas for male respondents it was the ninth in importance. For females, in almost all cases, husbands and boyfriends were cited as the ones responsible for the rescheduling. For males, close relatives were more often held responsible. These influences are also included in other theoretical frameworks reviewed in this study: Hägerstrand's coupling constraint (Hägertrand, 1970); Bandura's social environmental factor (Bandura, 1986); and Clark and Doherty's interpersonal factor (Clark and Doherty, 2009).

\subsection{Rescheduling reasons by type of travel mode}

The type of travel mode rescheduled turns out to be significantly associated with the reasons for rescheduling. The main reason in our sample for changing from one pre-planned private vehicle use to another (e.g. car driver to car passenger) was Social influence. Most of these cases were women who implemented the trip as car passengers rather than as car drivers as had 
been pre-planned. Secondly, the rescheduling decision was Constrained by a previous decision. Other reasons to pre-plan a PV and to execute another PV were associated with Resources (car availability) and the Opportunity of a new travel option. The decision to share a car emerged as an important reason as well. Interestingly, Location change and Location of a new/added activity were mentioned to a lesser extent as reasons to reschedule the use of PV by another PV.

On the other hand, if the use of PV was pre-planned and the trip was executed using NPV, the main reason for that rescheduling decision was a change in the Location of the preplanned activity. In many cases respondents performed the same activity they had pre-planned but at a closer location, or the new location offered better access with NPV. Secondly, there is a distinction in the available Resources they referred to, one being the lack of availability of the PV for various reasons, such as someone else in their household using it or that it had broken; the other being that they realized that a NPV was more convenient. The location of a spontaneous activity (not-pre-planned) was also an important reason for rescheduling their travel mode agenda. In some cases, activities added en route to the previously planned activity caused them to rethink the travel mode they should use.

Almost a half of rescheduling changes involved pre-planning NPV (221 out of 473, $46,7 \%)$. Only in a small percentage $(19,5 \%, 43$ out of 221$)$ was the change from one NPV to another, for diverse reasons such as the location change of the pre-planned activity, using the resources available, or different travel needs.

However, what we find most interesting, are those trips pre-planned using NPV and in the end fulfilled by a PV. The main reason for this rescheduling was Constrained by a previous decision, so a prior travel decision involving using a car or a motorbike, has restricted the rest of the trips that day to the same travel mode. A secondary reason is the Location of a spontaneous activity, or the change of the Location of the pre-planned activity. In this case, contrary to the pre-planned use of PV being fulfilled by NPV, this new location usually implies 
a greater distance, which is easier to reach by PV, and this new activity added to the agenda makes it more difficult to execute the whole chain of activities using NPV. In this case (changing NPV for PV), a new reason comes to the fore, it being the opportunity or the emergence of a new travel option. These are those trips that had been pre-planned in NPV but were finally carried out with other people in their private vehicles.

Interestingly, in more than a half of travel rescheduling decisions that involved preplanning NPV and executing PV, the NPV was walking. Moreover, Constrained, Location change of a pre-planned activity and Location of a new activity are the reasons given by respondents to explain this change. The reschedule of a walking trip to implement it instead by PV is also associated with Weather (rainy or extremely sunny).

\subsection{Theoretical frames}

Although some results are aligned with the Social Cognitive Theory of Bandura, and Hägerstrand's constraints of people's choices, the psychological theory that best explains the results presented in this paper is the Theory of Planned Behavior (TPB) (Ajzen, 1991).

We are interested in scrutinizing what happens between what is pre-planned and what an individual actually ends up doing. Ajzen's theory proposes that attitudes, subjective norms and perceived behavioral control precede the intention of doing something. Some people in our study were already planning to make their trips walking or in non-private vehicles, so the intention already existed. In those cases, we can assume a positive attitude toward sustainable travel modes, a social background that supports healthy lifestyles, and concern about nature and pollution.

In addition, we think our subjects also demonstrated management of appropriate information concerning schedules, stops and rules regarding public transportation, and a realistic assessment of their own ability to use them. Therefore, this finding suggests an intention to perform a certain action, and according to the TPB that intention leads to behavior. 
However, we have observed that in some cases, that intention is not translated into consistent behavior. The determinants involved in rescheduling decisions associated with travel modes are indentified in this paper.

\subsection{Findings and travel policy implications}

Almost all reasons found by Mars and Ruiz (2016) associated with the elimination of activities (pre-planned activities that are not carried out) that also cause the elimination of trips are also associated with rescheduling travel modes: social influence, weather, resources, travel needs (activity timing/duration), and location change. Only scheduled activities that conflict with spontaneous activities are related to the elimination of activities (and trips), and are not involved in travel mode rescheduling.

New determinants of rescheduling decisions different from those associated with elimination decisions emerge when analyzing travel mode changes. The influence of previous travel mode rescheduling in the agenda (Constrained) indicates a clear interrelation between travel mode rescheduling decisions, which is not so evident in scheduling decisions such as elimination or addition. Other new determinants are: having the chance to use a travel mode other than the one previously planned (Opportunity/new travel option); an active intention to share a vehicle with relatives, friends or colleagues (decision to share a car); spontaneous personal decisions to reschedule a travel mode based on likes and dislikes (Travel subjectivepreference); reasons related to security, safety, carrying luggage, fatigue or bad-health (Personal needs); and changing car driver to car companion or vice versa, depending on the presence of the usual driver (Habit).

As mentioned in the Introduction section, a better understanding of the reasons associated to activity-travel rescheduling decisions is needed to improve desing and implementation of soft travel measures. A number of sustainable transportation policy implications to reduce car use in urban areas can be derived from this study: 
- We have observed that people do not take into account as much as might be predicted all the activities to be performed during the day when they make travel mode decisions. Therefore, programs designed to change travel behaviors, for example to motivate people to reduce car use in urban areas, should include actions that train people to select travel modes taking into account all the activities they intend for the day.

- Individual social networks should be taken into account when defining and implementing strategies to promote the use of sustainable travel modes.

- Results of this study confirm the need for the promotion of local shopping and flexible policies of work/study locations to replace car use with alternative travel modes (Banister, 2008). The increase of activity diversity location or mixed land use would decrease travel distances, which benefits the use of active travel modes.

- Considering the number of reschedulings between private travel modes, there is potential to promote carpooling and carsharing strategies in order to reduce car use.

- To encourage the use of alternative travel modes to car for multi-stop journeys, it would be needed to enhance the multimodal transport system. For example, in multimodal fare systems, time between transfers should be long enough to accomplish the activities to be performed at those stops.

\section{CONCLUSIONS}

This paper presents methods and results of a qualitative analysis of the activity rescheduling process. Open-ended answers provided by frequent drivers related to decisions to modify the travel mode of pre-planned trips were analyzed using a new methodology adapted from Taylor and Bogdan's (1975) version of Analytic Induction. We have detailed the process followed in the application of the methodology, specifically how we established the codification that has allowed us to categorize all the data, facilitating the understanding of the reasons for 
rescheduling decisions. Furthermore, the amount of available data has also permitted us to study frequency distributions of those reasons by demographics and type of travel mode change.

Mars and Ruiz (2016) studied the reasons associated to elimination decisions during the activity scheduling process. In this paper, we focus on analysing a more specific modification: the reasons for travel mode reschedulings. We have identified 12 determinants or reasons to reschedule travel modes. Six determinants that explain the latter scheduling decisions are different from the reasons identified by Mars and Ruiz (2016): constrained decisions, opportunity/new travel options, decisions to share a car, travel (subjective) preference, personal needs, and habit. In our sample of 473 rescheduling cases, the most frequent factors are related to previous decisions to change (Constrained), and modifications of the activity agenda that cause a change in travel distances (Location change of a pre-planned activity; Location of a new added activity). These findings highlight the need to study rescheduling decisions taking into account their interrelations with other activities and trips in the agenda.

The influence of other people is also an important determinant in the rescheduling of travel modes (Social influence). Those decisions are shared most frequently when rescheduling travel modes, especially in the case of women. Other determinants are resources, opportunity or new travel options, weather, travel needs, decision to share a car, travel subjective preferences, personal needs and habits.

Limitations of the present study are mainly related to the sample size and the sample characteristics. A larger sample would allow identifying rescheduling reasons associated with specific travel mode changes. In addition, a larger sample would permit developing a quantitative analysis on how people reschedule travel modes. This quantitative analysis requires a larger sample, so that statistical models can be used. On the other hand, older than 50 are infra-represented in the sample. Moreover, all participants were habitual drivers, because the objective of the main study was to analyze the effect of a travel behavior change program. 
We plan to extend this study to rescheduling decisions related to other activity and trip attributes. It would also be convenient to replicate this research in other (larger) samples and in other cities, in order to confirm the determinants found and their relative importance. Travel decisions can also be analyzed in terms of social practices rather than behaviors (Cairns et al., 2014). Therefore, a combination of research methodologies could be applied to identify other factors that contribute to explain the decisions that people make related to their daily travels.

\section{ACKNOWLEDGMENTS}

The data used in this study was collected within the framework of MARYPOSA project founded by the Spanish Ministerio de Ciencia e Innovación (E29/08). This research is partially funded by MINERVA project founded by the $\mathrm{I}+\mathrm{D}+\mathrm{i}$ National Program of Society Challenges of the Spanish Ministerio de Economía, Industria y Competitividad (TRA2015-71184-C2-1$\mathrm{R})$.

\section{REFERENCES}

Adler, T., \& Ben-Akiva, M. (1979) A theoretical and empirical model of trip chaining behavior. Transportation Research Part B: Methodological, 13 (3), 243-257.

Ajzen, I. (1991). The theory of planned behavior. Organizational behavior and human decision processes, 50 (2), 179-211.

Ajzen, I., \& Fishbein, M. (1980). Understanding attitudes and predicting social behavior. New Jersey: Prentice-Hall, Inc

Ajzen, I., \& Fishbein, M. (2005). The influence of attitudes on behavior. In D. Albarracín, B. T. Johnson, \& M. P. Zanna (Eds.), The handbook of attitudes (pp. 173-221). Mahwah, NJ: Erlbaum.

Arentze, T., \& Timmermans, H. (2000). Albatross: a learning based transportation oriented simulation system (pp. 6-70). Eindhoven: Eirass. 
Auld, J., Williams, C., Mohammadian, A., \& Nelson, P. (2009). An automated GPS-based prompted recall survey with learning algorithms. Transportation Letters, 1 (1), 59-79.

Axhausen, K. W., \& Gärling, T. (1992). Activity-based approaches to travel analysis: conceptual frameworks, models, and research problems. Transport Reviews, 12 (4), 323-341.

Badland, H., \& Schofield, G. (2005). Transport, urban design, and physical activity: an evidence-based update. Transportation Research Part D, 10 (3), 177-196.

Bandura, A. (1986). Social foundations of thought and action: A social cognitive theory. Prentice-Hall, Inc.

Banister, D. (2008). The sustainable mobility paradigm. Transport policy, 15 (2), 73-80.

Baxter, P., \& Jack, S. (2008). Qualitative case study methodology: Study design and implementation for novice researchers. The qualitative report, 13 (4), 544-559.

Ben-Akivai, M., Bowman, J. L., \& Gopinath, D. (1996). Travel demand model system for the information era. Transportation, 23 (3), 241-266.

Canzler, W. (2016). Mobility in the age of digital modernity: why the private car is losing its significance, intermodal transport is winning and why digitalisation is the key. Applied Mobilities, 1, 56-67.

Cao, X., \& Mokhtarian, P. L. (2005). How do individuals adapt their personal travel? Objective and subjective influences on the consideration of travel-related strategies for San Francisco Bay Area commuters. Transport Policy, 12 (4), 291-302.

Chapin Jr, F. S. (1974). Human activity patterns in the city. Things People Do in Time and Space. New York ua: John Wiley \& Sons

Chen, C. F., \& Chao, W. H. (2011). Habitual or reasoned? Using the theory of planned behavior, technology acceptance model, and habit to examine switching intentions toward public transit. Transportation Research Part F: Traffic Psychology and Behaviour, 14 (2), 128-137.

Chen, C., Gärling, T., \& Kitamura, R. (2004). Activity rescheduling: reasoned or habitual?. Transportation Research Part F: Traffic Psychology and Behaviour, 7 (6), 351-371.

Clark, A., \& Doherty, S. (2009). Activity rescheduling strategies and decision processes in day-to-day life. Transportation Research Record: Journal of the Transportation Research Board, (2134), 
$143-152$.

Clark, A. F., \& Doherty, S. T. (2010). A multi-instrumented approach to observing the activity rescheduling decision process. Transportation, 37 (1), 165-181.

Clifton, K. J., \& Handy, S. L. (2001). Qualitative methods in travel behaviour research. Institute of Transportation Studies. University of California, Davis.

Cohen, J. (1960). A coefficient of agreement for nominal scales. Educational and Psychological Measurement, 20, 37-46.

Cresswell, T., \& Priya Uteng, T. (2008). Gendered mobilities: Towards an holistic understanding. In Gendered Mobilities (Cresswell and Priya Uteng, eds), Routledge, New York.

Cullen, I., \& Godson, V. (1975). Urban networks: the structure of activity patterns. Progress in planning, $4,1-96$.

Dill, J. (2009). Bicycling for transportation and health: the role of infrastructure. Journal of public health policy, 30, Supplement 1, S95-S110.

Doherty, S. T., \& Miller, E. J. (2000). A computerized household activity scheduling survey. Transportation, 27 (1), 75-97.

Elliot, A., \& Urry, J. (2010). Mobile Lives. Routledge, New York.

Ferrer, S., Ruiz, T. \& Mars, M. (2015) A qualitative study on the role of the built environment for short walking trips. Transportation Research Part F, 33, 141-160.

Fleiss, J. L. (1981). Statistical methods for rates and proportions. New York: Wiley.

Flick, U. (2014). An introduction to Qualitative Research. SAGE publications.

Gardner, B., \& Abraham, C. (2007). What drives car use? A grounded theory analysis of commuters' reasons for driving. Transportation Research Part F: Traffic Psychology and Behaviour, 10 (3), 187-200.

Habib, K. N., Sasic, A., Weis, C., \& Axhausen, K. (2013). Investigating the nonlinear relationship between transportation system performance and daily activity-travel scheduling behaviour. Transportation Research Part A: Policy and Practice, 49, 342-357.

Hägerstraand, T. (1970). What about people in regional science?. Papers in regional science, 24 (1), 7 24. 
Helbich, M., van Emmichoven, MJZ, Dijst, MJ, \& Kwan, MP. (2016). Natural and built environmental exposures on children's active school travel: A Dutch global positioning system-based crosssectional study. Health \& Place, 39, 101-109.

Jones, P. M., Dix, M. C., Clarke, M. I., \& Heggie, I. G. (1983). Understanding travel behaviour (Aldershot: Gower).

Knafl, K. A., \& Breitmayer, B.J. (1989). Triangulation in qualitative research: Issues of conceptual clarity and purpose. Qualitative nursing research: A contemporary dialogue, 226, 193-203.

Kitamura, R. (1984) Incorporating trip chaining into analysis of destination choice. Transportation Research Part B, 18, 1, 67-81.

Landis, J. R., \& Koch, G. G. (1977). The measurement of observer agreement for categorical data. Biometrics, 33 (1), 159-174.

Lois, D., Moriano, J. A., \& Rondinella, G. (2015). Cycle commuting intention: A model based on theory of planned behaviour and social identity. Transportation research part F: traffic psychology and behaviour, 32, 101-113.

Loukopoulos, P., \& Gärling, T. (2005). Are car users too lazy to walk? The relationship of distance thresholds for driving to the perceived effort of walking. Transportation Research Record, 1926, 206-211.

Maibach, E., Steg, L.. \& Anable, J. (2009). Promoting physical activity and reducing climate change: Opportunities to replace short car trips with active transportation. Preventive medicine, 49, $326-327$.

Manderscheid, K. (2014). The movement problem, the car and post-Fordist mobility: Automobility as dispositif and mode of regulation. Mobilities, Special Issue: Foucault and Mobilities Research. 4/9, 604-626.

Mars, L., \& Ruiz, T. (2016). Determinants of eliminations decisions in the activity scheduling process. Transportation Letters. Published online. http://dx.doi.org/10.1080/19427867.2016.1242882.

Maslow, A. H. (1943). A theory of human motivation. Psychological review, 50 (4), 370.

Mateo-Babiano, I. (2016). Pedestrian's needs matters: Examining Manila's walking environment. 
Transport Policy, 45, 107-115.

Milles, M. B., \& Hubermann, A. M. (1994). Qualitative data analysis. An expanded sourcebook. SAGE Publications.

McGuckin, N. \& Murakami, E. (1999). Examining Trip-Chaining Behavior: Comparison of Travel by Men and Women. Transportation Research Record: Journal of the Transportation Research Board, 1693, 79-85

McGuckin, N., Zmud, J., \& Nakamoto, Y. (2005). Trip-Chaining Trends in the United States: Understanding Travel Behavior for Policy Making. Transportation Research Record: Journal of the Transportation Research Board, 1917, 199-204.

Millward, H., Spinney, J. \& Scott, D. (2013) Active-transport walking behavior: destinations, durations, distances. Journal of Transport Geography, 28, 101-110.

Mokhtarian, P. (2005a). The positive utility of travel. Transportation Research, 39 (2-3).

Mokhtarian, P. (2005b). Travel as a desired end, not just a means. Transportation Research Part A: Policy and Practice 39 (2), 93-96

Nijland, E. L., Arentze, T. A., Borgers, A. W., \& Timmermans, H. J. (2009). Individuals' Activity-Travel Rescheduling Behaviour: Experiment and Model-Based Analysis. Environment and Planning $A, 41(6), 1511-1522$.

Peters, P. (2005) Exchanging travel speed: time politics in mobility practices. Configurations, 13 (3), $395-419$.

Rau, H., \& Edmondson, R. (2013). Time and sustainability. Methods of sustainability research in the social sciences, 173-190. http://dx.doi.org/10.4135/9781526401748.n9

Roorda, M. J., Miller, E. J., \& Habib, K. M. (2008). Validation of TASHA: A 24-h activity scheduling microsimulation model. Transportation Research Part A: Policy and Practice, 42 (2), 360375.

Ruiz, T. (2005). The design and implementation of an activity scheduling survey using the internet. In Progress in Activity-Based Analysis. H. Timmermans, ed. Elsevier, Dordrecht, Netherlands, pp. 373-388.

Ruiz, T., \& García-Garcés, P. (2015). Measuring the impact of travel behavior change programs on the 
activity scheduling process. Transportation Letters, 7 (2), 104-113.

Ruiz, T. and Mars, L. (2017). Determinants of Elimination Decisions in the Activity Scheduling Process. Transportation Letters. The International Journal of Transportation Research (in press). https://doi.org/10.1080/19427867.2016.1242882

Shaheen, S., Allen, D., \& Liu, J. (2008). Public transit training: a mechanism to increase ridership among older adults. Institute of Transportation Studies. Transportation Research Board Annual Meeting. Washington, DC.

Sheller, M. \& Urry, J. (2000) The city and the car. International Journal of Urban and Regional Research 24 (4), 737 - 757.

Taylor, S., \& Bogdan, R. (1975). Introduction to qualitative research method. A phenomenological approach to the social sciences. John Wiley \& Sons, Inc., New York.

Thomas, G. O., Walker, I., \& Musselwhite, C. (2014). Grounded Theory analysis of commuters discussing a workplace carbon-reduction target: Autonomy, satisfaction, and willingness to change behaviour in drivers, pedestrians, bicyclists, motorcyclists, and bus users. Transportation research part F: traffic psychology and behaviour, 26, 72-81.

Wuerzer, T. \& Mason, S.G. (2015) Cycling willingness: investigating distance as a dependent variable in cycling behavior among college students. Applied Geography, 60, 95-106.

Znaniecki, F. (1934). The method of sociology. Farrar \& Rinehart, New York. 